\title{
Society for Pediatric Research Presidential Address 1994: Yeast as Metaphor
}

\author{
MARGARET K. HOSTETTER \\ Department of Pediatrics, University of Minnesota, Minneapolis, Minnesota 55455
}

\begin{abstract}
About 7 years ago, I was asked to evaluate an 8-monthold boy who had been devastated by pneumococcal meningitis. On intravenous hyperalimentation and Decadron for irreversible brain edema, he now had positive blood and urine cultures for Candida albicans. And had I been able to peer into that baby's bloodstream, I would have viewed an epic battle between yeast and neutrophil: on the one side, a primitive eukaryotic cell, on the other, a sophisticated killing machine (Fig. 1).
\end{abstract}

Such a story is all too common today, with $C$. albicans the leading cause of fungal infection in our hospitals. But why Candida? Why not some other yeast, like Saccharomyces cerevisiae? Both of these species are indigenous to the human gastrointestinal tract, and many of the genes encoding structural proteins, such as tubulin or actin, are identical. And yet $S$. cerevisiae is invariably kind to us, whereas $C$. albicans causes more than $60 \%$ of all fungal infections, with a fatality rate that approaches $30 \%$, even with appropriate antifungal therapy.

In the quest for answers, there were some superficial starting points. For example, like my patient, the host who develops candidal fungemia typically evidences one or more risk factors. Antibiotic use, hyperglycemia, steroids, indwelling catheters, and neutropenia-each may be invoked when neonates, diabetics, intensive care unit patients, or neutropenic hosts develop invasive candidal infection, and yet none of these, singly or together, explains the disease.

Then we were greatly helped in our search by two observations: First, Heidenreich and Dierich (1) reported that sheep erythrocytes bearing the $\mathrm{C} 3$ fragment $\mathrm{iC} 3 \mathrm{~b}$ rosetted with pseudohyphae from $C$. albicans. Subsequently, Edwards (2) demonstrated that a murine monoclonal antibody, recognizing the type 3 human complement receptor (CR3), bound to $C$. albicans pseudohyphae. These observations therefore suggested that $C$. albicans bore specialized surface proteins that mimicked the complement receptors on human leukocytes, CR3 and its closely related homolog CR4, members of the $\beta_{2}$ subset of the integrin superfamily. Integrins direct adhesion and cell-to-cell communication on a host of eukary-

Correspondence: Margaret K. Hostetter, M.D., Division of Pediatric Infectious Diseases, University of Minnesota, Box 296, 420 Delaware St. S.E., Minneapolis, MN 55455 .

This work was supported by grants from the National Institutes of Health (AI24162, AI25827, T32 HD07381) and from the Pediatric AIDS Foundation. otic cells (Fig. 2) (3) and are thought to have evolved from a primordial gene, as yet undiscovered, but it was a great leap for these investigators, across more than one billion years of evolution, to surmise that a primitive and unsophisticated little yeast might hold the key to an evolutionary mystery.

I will briefly describe the evidence for the classification of these candidal complement receptors as integrin analogs and for the primacy of their role as adhesins in the pathogenesis of candidal infection.

The mammalian integrins, a family of $16 \alpha$-subunits and eight $\beta$-subunits, are expressed as heterodimeric transmembrane proteins on a wide variety of mammalian cells. In present taxonomy, integrins are grouped in subsets on the basis of their $\beta$-subunits. As shown in Figure 2, two of the $\beta_{2}$ integrins share antigenic, structural, and functional homologies with candidal surface proteins: $\alpha_{M}$, which is also known as Mac-1, CD11b, or CR3, and $\alpha_{\chi}$, which is known as p150,95, CD11c, or CR4. $\alpha_{M}$ and $\alpha_{x}$ are polypeptides of 165 and $150 \mathrm{kD}$, respectively; in leukocytes, they are expressed in association with a common $\beta$-subunit of $95 \mathrm{kD}$.

There are several functional domains on mammalian integrins that deserve special mention. Both the $\alpha$ - and $\beta$-subunits have distinct cytosolic tails that mediate intracellular signaling via interactions with actin and talin, and both have highly conserved transmembrane domains (3). In the extracellular region, $\alpha_{M}$ and $\alpha_{x}$ exhibit an inserted domain, or I-domain, that binds the C3 ligand $\mathrm{iC} 3 \mathrm{~b}$ and is recognized by the monoclonal antibody $\mathrm{Mn} 41$. In addition, there are three calcium-binding sites that are required for ligand binding. Lastly, the carboxy terminus of the extracellular domain is recognized by a second monoclonal antibody, called OKM1.

It is presently thought that the extracellular domains of both the $\alpha$ - and $\beta$-subunits cooperate in the recognition and binding of integrin ligands in the extracellular matrix; many but not all of these ligands are distinguished by the tripeptide sequence of arginine, glycine, aspartic acid, or RGD.

Graphic evidence of antigenic relationship between the mammalian $\beta_{2}$ integrins and integrin analogs in yeast is this immunofluorescent micrograph from our laboratory, in which incubation of yeast-phase $C$. albicans with anti- $\alpha_{M}$ monoclonal antibodies such as anti-Mo1-94 results 


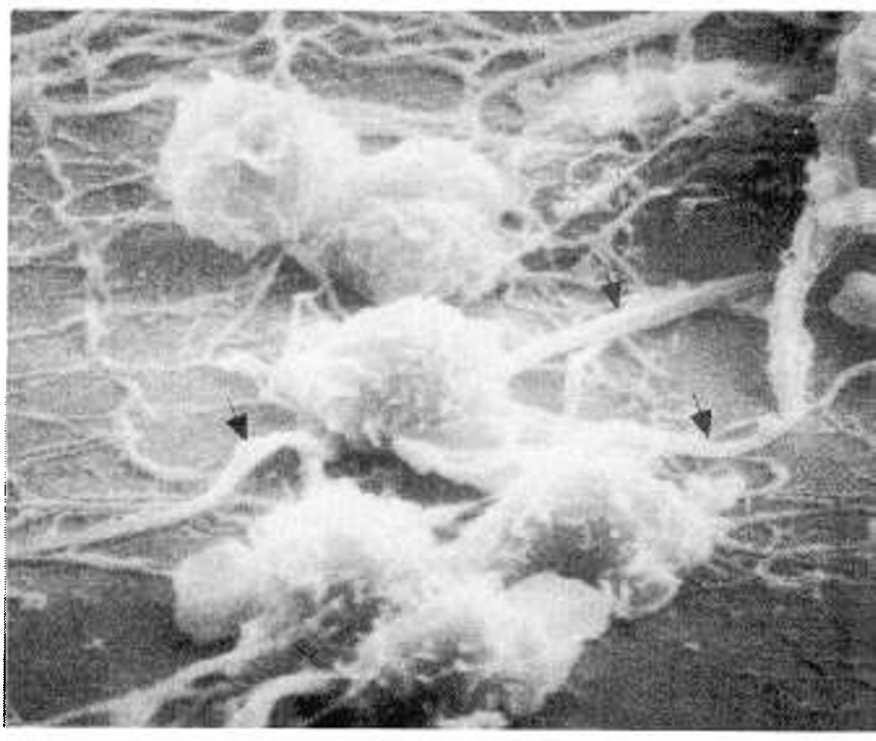

Figure 1. Scanning electron micrograph of $C$. albicans pseudohyphae and human neutrophils $(\times 5000)$ (reprinted from Gower DJ, Crone K, Alexander E, Kelly DC 1986 Candida albicans shunt infection: report of two cases. Neurosurgery 19:111-113, with the permission of the publisher).

in circumferential immunofluorescence (Fig. 3, panel B), whereas incubation with isotype controls yields no fluorescence (Fig. 3, panel D).

In our laboratory, we have used flow cytometry with saturating concentrations of anti- $\alpha_{M}$ monoclonal antibodies to quantitate expression of the integrin analog among several species of yeast (Table 1). For any given $C$. albicans isolate, nearly $80 \%$ of the population binds a variety of integrin monoclonal antibodies, whereas expression is considerably reduced in other Candida species and virtually absent in $S$. cerevisiae. This hierarchy of fluorescence accords quite closely with the frequency of isolation of $C$. albicans and other yeast species from immunocompromised hosts (Table 1): C. albicans is most frequent, followed by other Candida species and, lastly, by $S$. cerevisiae.

In addition, conditions of clinical relevance such as hyperglycemia, use of steroids, or temperature may also influence integrin expression. Growth of yeast cells in medium containing $\geq 20 \mathrm{mM}$ D-glucose, growth in the presence of $10^{-9} \mathrm{M}$ hydrocortisone, or growth at $37^{\circ} \mathrm{C}-$ all increase expression of the integrin analog in C. albicans by as much as 2- to 6 -fold $(4,5)$. These conditions suggest not only possible clinical correlates but potential regulators of integrin gene expression as well.

Structural similarities are no less intriguing. You will recall that $\alpha_{M}$ and $\alpha_{x}$ had molecular masses of 165 and $150 \mathrm{kD}$, respectively. Isolation of the integrin analog from a cytosolic extract of $C$. albicans yields a single band of $165 \pm 15 \mathrm{kD}$ under nonreducing conditions.

Functional analogies between the leukocyte integrins and the integrin analog in C. albicans include the binding of the ligand iC3b with identical affinity constants (4). This suggests that both candidal and mammalian inte-

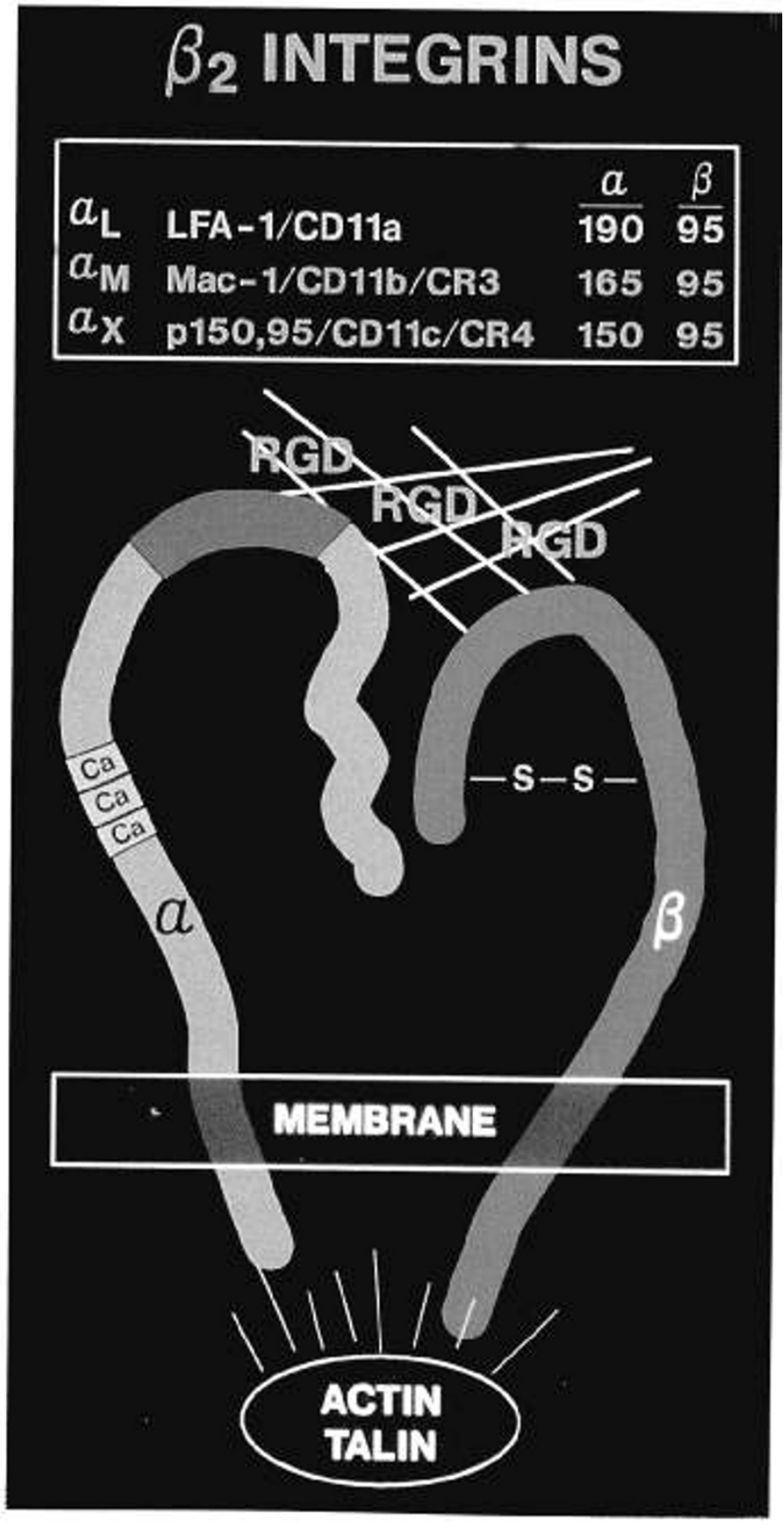

Figure 2. Model of functional domains of the $\beta_{2}$ integrins in mammalian cells (modified from Albelda SM, Buck CA 1990 Integrins and other cell adhesion molecules. FASEB J 4:2868-2880).

grins contain an I-domain. Moreover, the conceptual model (Fig. 2) indicates that integrins in mammalian cells mediate adhesion to other eukaryotic surfaces, typically by recognition of RGD sequences in matrix proteins.

Similarly, in C. albicans, adhesion to the epithelium of the gastrointestinal tract stands as a first step in the pathogenesis of candidal infection. Having colonized the host's mucosal surfaces, C. albicans and some related species may then invade beneath the mucosal barrier, enter the vascular space, and replicate with impunity to cause hematogenously disseminated disease. We therefore asked whether epithelial adhesion of $C$. albicans could 

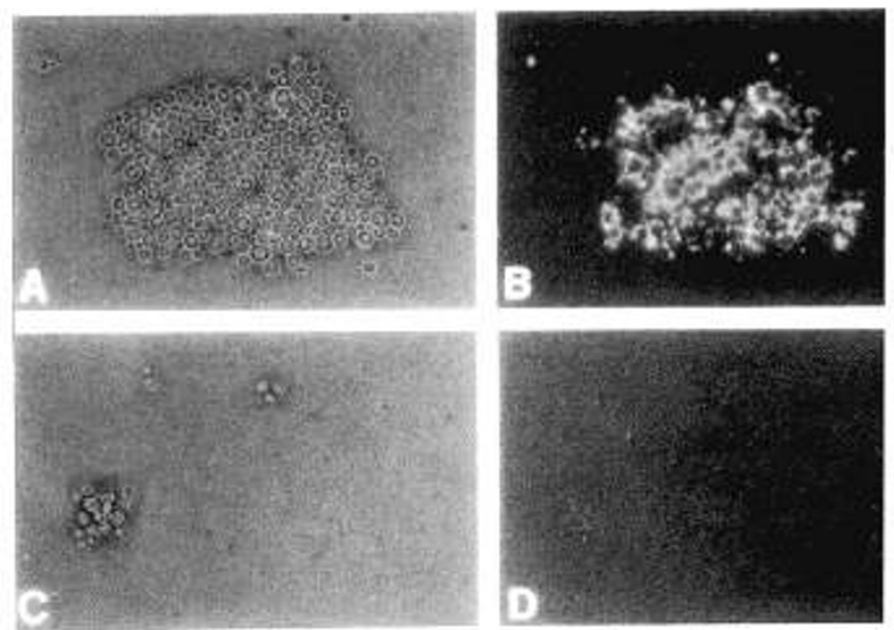

Figure 3. Phase-contrast $(A, C)$ and immunofluorescence microscopy $(B, D)$ of a blood isolate of $C$. albicans after incubation with antiMo1-94 $(B)$ or the isotype control MsIgM $(D)$ (micrograph is reprinted from Gustafson KS, Vercellotti GM, Bendel CM, Hostetter MK 1991 Molecular mimicry in Candida albicans: role of an integrin analog in adhesion of the yeast to human endothelium. J Clin Invest 87:18961902 , with permission of the publisher).

involve RGD sequences and, if so, whether we could use these strategies to block adhesion and possibly to avert the subsequent complications of invasive infection.

Using cervical epithelial cells, Dr. Catherine Bendel demonstrated that the degree of epithelial adhesion in Candida species reproduced quite closely the pattern of integrin expression quantitated by flow cytometry: epithelial adhesion was greatest for $C$. albicans, reduced for other Candida species, and virtually absent in $S$. cerevisiae (Table 1).

However, the contention that the integrin analog mediates epithelial adhesion requires more explicit evidence, both at the level of the yeast and from the standpoint of the epithelial cell. By immunofluorescence and immunoprecipitation, Dr. Eric Michael and Dr. Bendel (7) demonstrated that epithelial cells secrete at least two potential ligands for yeast adhesion: $\mathrm{iC} 3 \mathrm{~b}$ and fibronectin.

In $\mathrm{iC} 3 \mathrm{~b}$, the RGD tripeptide is localized to the carboxy terminus of the $\alpha^{\prime}$ chain; in contrast, the C3d subdomain is more centrally located within the $\alpha^{\prime}$ chain and can be excised from the iC3b molecule but does not contain an

Table 1.

\begin{tabular}{lccc}
\hline & $\begin{array}{c}\text { Percentage of } \\
\text { isolates from } \\
\text { immunocompromised } \\
\text { Yosts* }\end{array}$ & $\begin{array}{c}\text { Percentage } \\
\text { fluorescing } \\
\text { with OKM1 } \dagger\end{array}$ & $\begin{array}{c}\text { Percentage of } \\
\text { adhesion to } \\
\text { epithelium } \ddagger\end{array}$ \\
\hline C. albicans & 68.5 & $73.4 \pm 3.6$ & $44.0 \pm 1.9$ \\
C. tropicalis & 12.9 & $23.2 \pm 6.6$ & $38.8 \pm 3.6$ \\
C. glabrata & 10.7 & $27.2 \pm 2.5$ & $12.0 \pm 6.5$ \\
C. parapsilosis & 3.7 & $6.1 \pm 1.9$ & $19.3 \pm 6.9$ \\
C. krusei & 1.5 & $0.4 \pm 0.2$ & $20.9 \pm 3.5$ \\
S. cerevisiae & 0.8 & $3.4 \pm 1.5$ & $9.9 \pm 3.6$ \\
\hline
\end{tabular}

* Data from Ref. 6.

$\dagger$ Data from Ref. 8.

$\ddagger$ Data from Ref. 8 .
RGD sequence. Similarly, among several binding domains for heparin, for collagen, and for fibrin, fibronectin contains an RGD sequence in its cell-binding domain. The amino acid sequences flanking the RGD peptide are quite different in fibronectin and $\mathrm{iC} 3 \mathrm{~b}$.

In experiments to block candidal adhesion, preincubation of $C$. albicans with $10-\mu \mathrm{M}$ concentrations of bovine serum albumin, fibronectin, or $\mathrm{C} 3 \mathrm{~d}$ had no effect on adhesion. In contrast, purified iC $3 b$ inhibited epithelial adhesion of $C$. albicans by $80 \%$ (Fig. 4). Additional experiments pointed to the importance of the RGD tripeptide in $\mathrm{iC} 3 \mathrm{~b}$ and its specific flanking sequence in mediating this interaction (Fig. 5). RGD peptides from $\mathrm{iC} 3 \mathrm{~b}$ that were less than nine amino acids in length, or a series of RGD peptides from fibronectin (seven to 23 amino acids) failed to block adhesion of $C$. albicans to epithelial cells. An RGK peptide was similarly ineffective. In contrast, RGD peptides of nine, 10, and 15 amino acids successfully blocked the adhesion of $C$. albicans to human epithelium, provided that they contained the correct iC3b flanking sequence (7).

This slide (Fig. 6) is affectionately called "the tapdancing yeasts," and in my book, C. albicans is the Fred Astaire of fungi. As $C$. albicans colonizes the oropharynx or the lumen of the gastrointestinal tract, its complement receptor or integrin analog contacts $\mathrm{iC} 3 \mathrm{~b}$ molecules studding the surface of the epithelial cell. Like the mammalian integrins, the integrin analog in C. albicans recognizes the RGD site and specific flanking residues in $\mathrm{iC} 3 \mathrm{~b}$, and adhesion occurs. By flow cytometry, protein, and genetic studies, species such as C. parapsilosis, C. glabrata, $C$. krusei, or $S$. cerevisiae fail to express an integrin analog and therefore lack the "adhesion advantage" that it confers.

This adhesive interaction can be interrupted from the epithelial side with antibodies to $\mathrm{iC} 3 \mathrm{~b}$, the secreted ligand, and from the candidal side with monoclonal antibodies against human $\alpha_{M}$ and $\alpha_{\chi}$, with purified iC3b or, excitingly, with our new iC3b peptides (7). The door

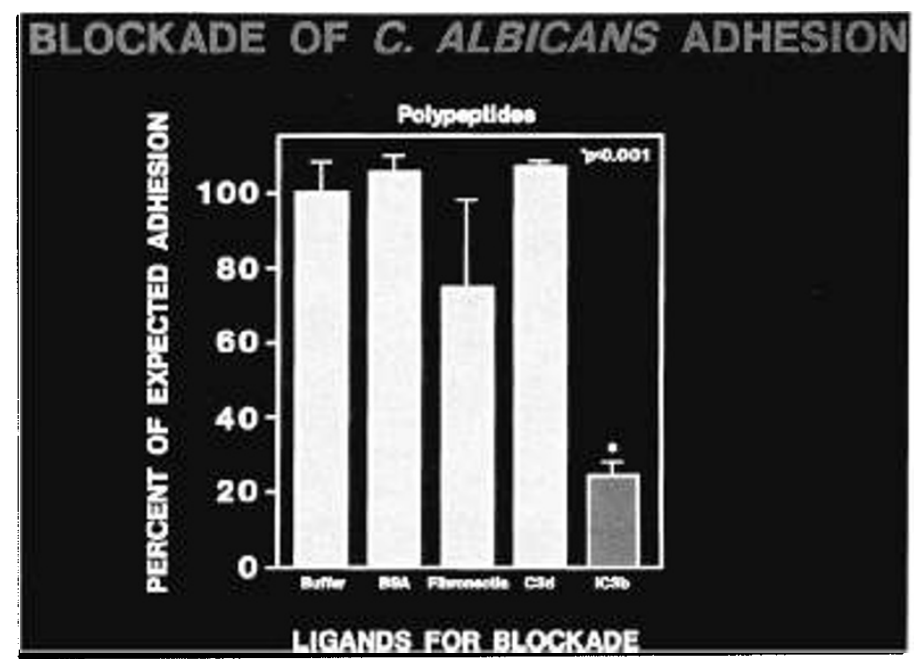

Figure 4. Blockade of $C$. albicans adhesion to human epithelium with purified proteins (data taken from Ref. 7). 


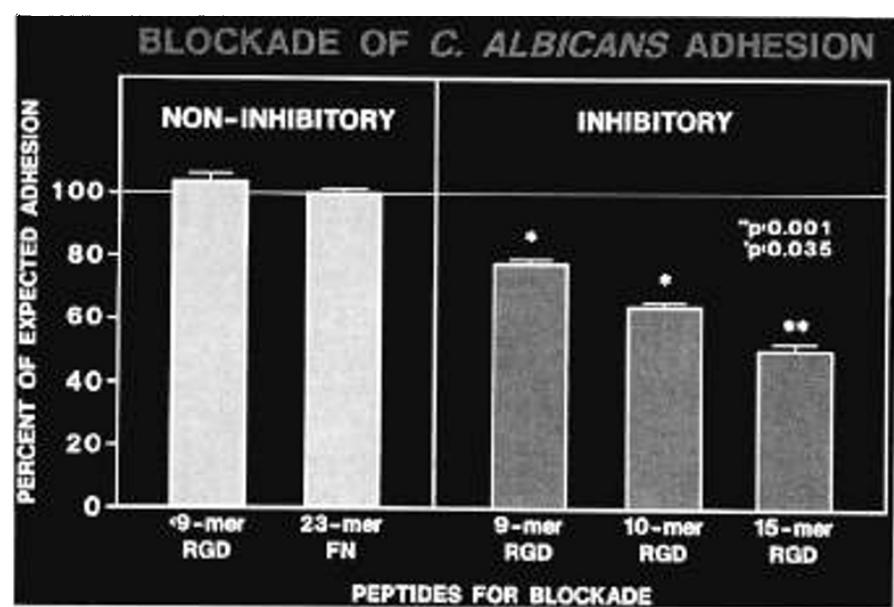

Figure 5. Blockade of $C$. albicans adhesion to human epithelium with RGD peptides (data taken from Ref. 7).

therefore opens to the possibility that we may be able to protect susceptible patients from candidal infection, or at least reduce their risk, by using these peptides to inhibit colonization.

Recent work from Greg DeMuri, Cheryl Gale, Mark McClellan, and Marilyn Meinke in my laboratory has led to the identification of several candidate integrin genes for $C$. albicans and related species. This model, once hypothesis but now fast becoming fact, should help to explain our present understanding of their relationships (Fig. 7).

In Saccharomyces cerevisiae, a nonadherent yeast, a gene encoding an intracellular myosin-like protein found in the cytoplasm surprisingly contains a sequence resembling an integrin I-domain. A fusion protein containing this portion of the gene product binds the I-domain ligand $\mathrm{iC} 3 \mathrm{~b}$ and is recognized by $\mathrm{Mn} 41$, the monoclonal antibody specific for this epitope. OKM1 and other integrin monoclonals do not bind. Lack of a signal sequence and the absence of a hydrophobic transmembrane domain

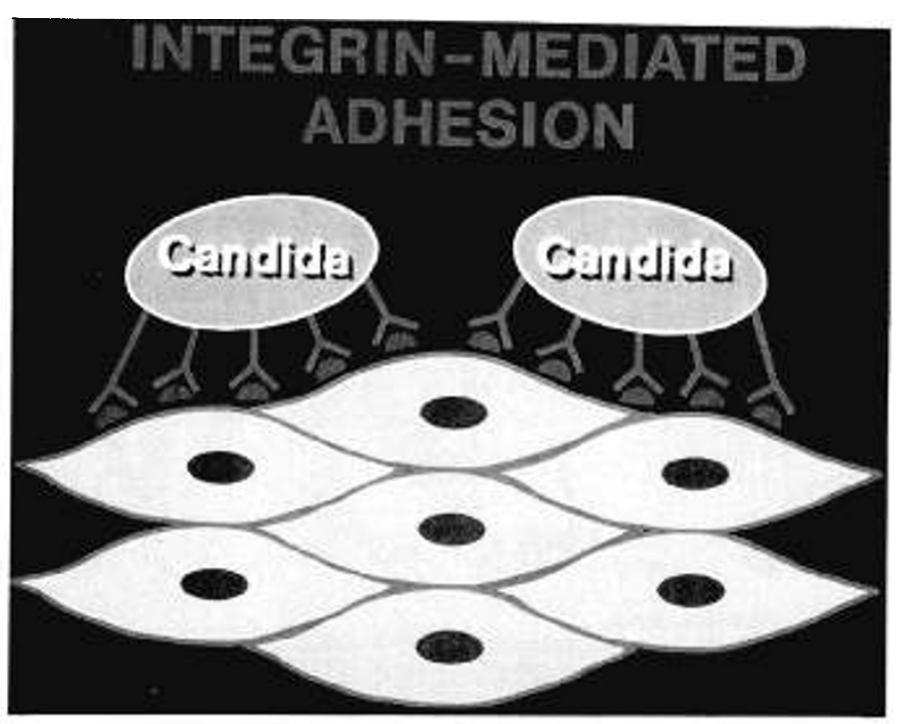

Figure 6. Interaction between the integrin analog and epithelially synthesized $\mathrm{iC} 3 \mathrm{~b}$ in the adhesion of $C$. albicans to human epithelium. relegate this protein to the cytosol in $S$. cerevisiae, where it functions in intracellular protein transport (9). Thus, failure of surface expression predicts failure of adhesion.

In $C$. albicans, in contrast, a $4.9-\mathrm{kb}$ open reading frame encoding a putative $\alpha$-subunit integrin analog has been isolated. The polypeptide structure of the gene product shows several possible areas of homology: an I-domain, a transmembrane region, and interestingly, its own RGD site for yeast aggregation. Thus, at least one candidal gene with $\alpha$-integrin homologies has been identified.

Analogs of the mammalian $\beta$-subunit have been identified in both $C$. albicans and $C$. tropicalis, the secondmost adherent candidal species (10). So we are now poised to understand the genes that encode a panoply of integrin-like proteins and, in the case of glucose and steroids, the promoters and regulatory elements that control them, as we move from primitive eukaryote to its more virulent cousin Candida and on to the mammalian cell.

The traditional stopping point, of course, is here, but to halt now would be to emphasize the facts at the expense of the metaphor. And that, as a former English major, I am forbidden to do, because we learn much from science apart from fact. What we learn biologically is that a simple yeast, a primitive eukaryote, carries genes related to a much more complex system in humans, reaching across eons of evolution to establish those commonalities of biologic conservation. What we learn philosophically is that we can take a worthy lesson from that yeast, and we can apply that lesson to our lives as investigators and as pediatricians.

\section{RESILIENCE}

The cell wall of $C$. albicans is $200 \mathrm{~nm}$ thick, thicker than Saccharomyces or virtually any other organism save plants (Fig. 8). Its six layers of chitin, $\beta$-glucans, and mannoproteins present a nearly impenetrable barrier to our pharmacologic armaments. This is one tough fungus. And Candida is a clever opportunist as well, seizing the breaches in host defense - the newborn, the neutropenic, the immunocompromised-for its attacks. And now I speak to the fellows and junior faculty in the audience, to the 400 of you who packed our educational symposia and who are the life's blood of this Society. If you as young investigators are to succeed in research for children, you too must toughen up and seize the opportunities. Don't be afraid to make mistakes. If it's good, it can be made better; if it's wrong, it can be righted. Don't be deterred by rejection. My papers are rejected, and my grants aren't always funded. When faced with adversity, act like a yeast. Take the punch; it's how you come back that counts.

\section{TRANSFORMATION}

One of the most bewildering mysteries in Candida is its uncanny ability to transform, from yeast to budding daughter cell to pluripotent hyphae (Fig. 9). In Candida, 


\section{EVOLUTION Of INTEGRINS (A Hypothetical Model)}

\section{S. CEREVISIAE}

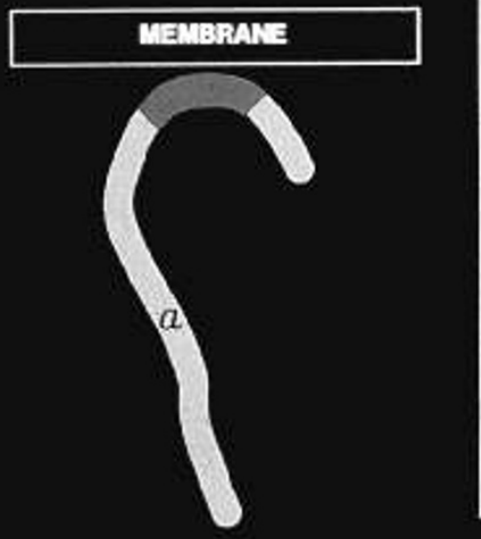

\section{ALBICANS}

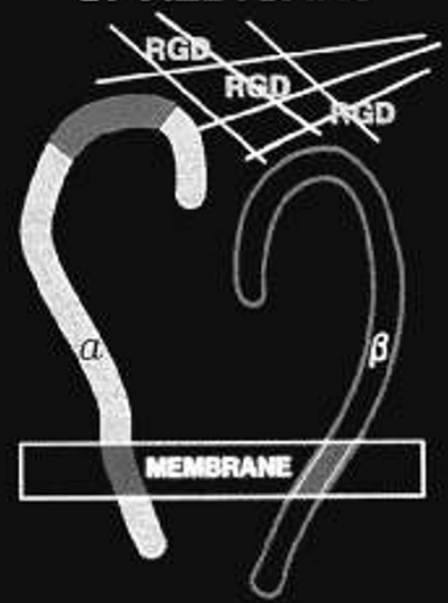

MAMMALS

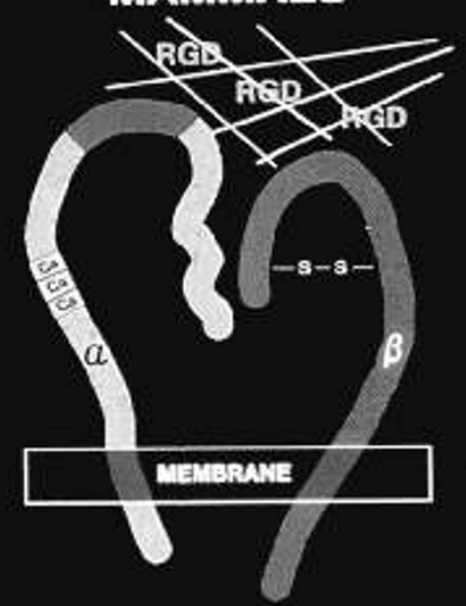

Figure 7. Model for evolution of integrins.

\section{RESILIENCE}

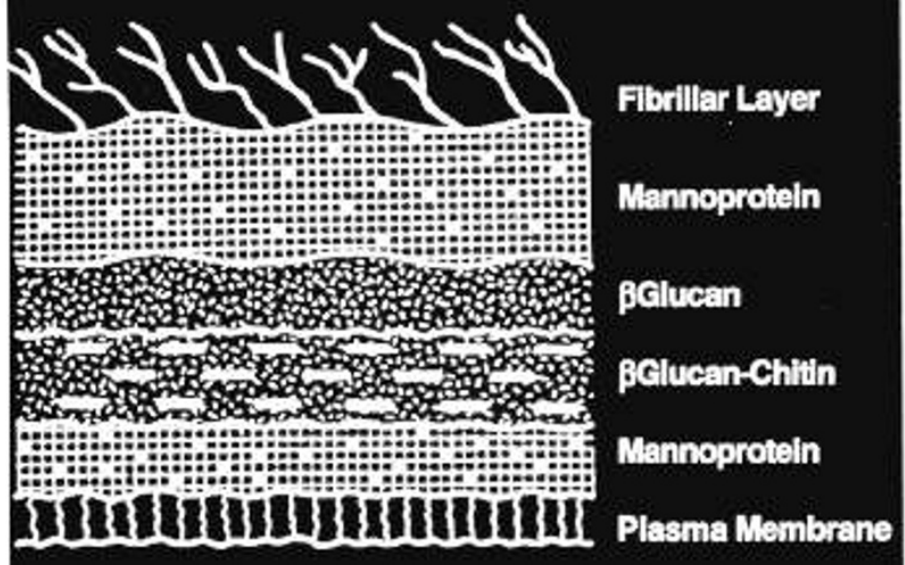

Figure 8. Schematic diagram of the seven layers of the candidal cell wall (reprinted from Shepherd MG 1987 Crit Rev Microbiol 15:7-25, with permission of the publisher).

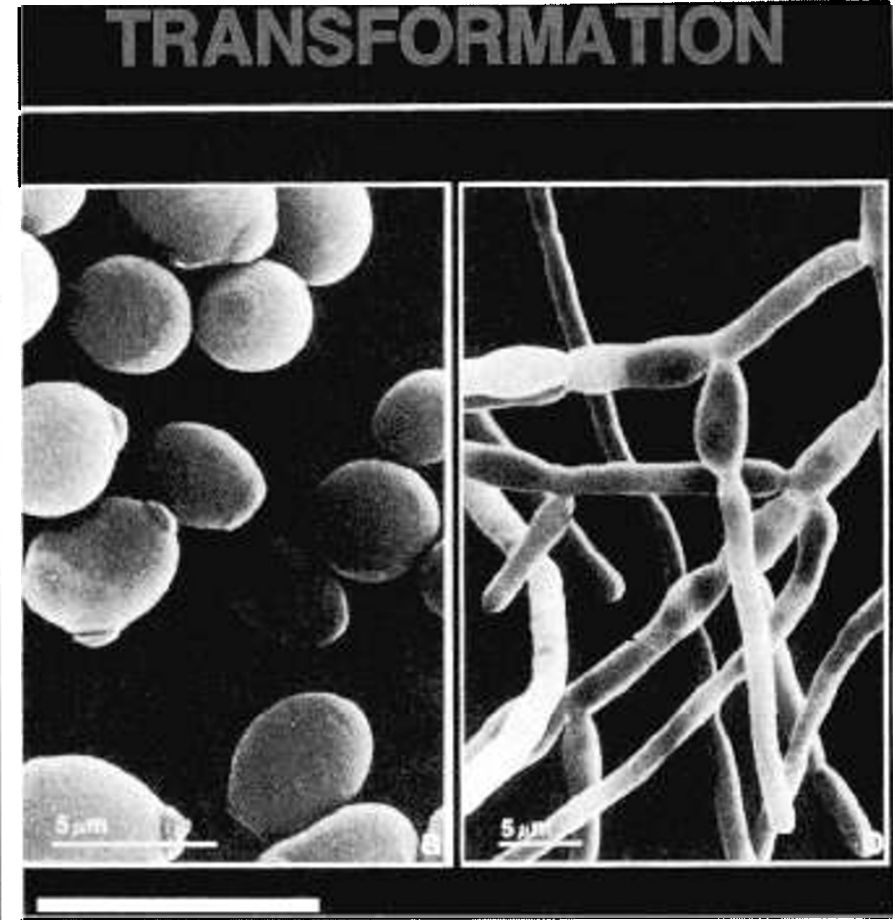

Figure 9. Figure is reprinted from Borgers M 1993 Morphological aspects of fungal dimorphism. In: Vanden Bossche H, Odds FC, Kerridge D (eds) Dimorphic Fungi. Plenum Press, New York, p 124, with permission of the publishers. 
this metamorphosis endows the organism with an unequaled pathogenic potential. Transformation also occurs in pediatrics, as these pictures show: the house staff of the pediatric service at Johns Hopkins, 1955-and here, for you archivists, is Dr. Mary Ellen Avery, one of my first mentors. Just 20 years later, we see Dr. Avery with her house staff at Boston Children's Hospital, 1975. What changes have ensued: from uniforms (or the lack thereof) to hairstyles and even to more subtle transformations. This era was one of unprecedented growth in academic medicine, in subspecialty training, and in the inclusion of women and minorities. Now, of course, we confront the next 20 years, and the future looks dark to many.

- What will we do with the 13 million children who have no health insurance? Tell them to wait until they are 65 ?

- What will we say to the hundreds of thousands of children who are hungry by day and homeless at night? Tell them they just don't count?

- What will we do to convince government, the press, and the lay public of the value of research for children?
We will transform ourselves yet again; we will become more adept, more versatile in the most adverse of circumstances; and we will say "Look with us at these faces."

Hyaline membrane disease - a thing of the past. Tuberculosis treated. Leukemia left behind on a summer afternoon. Asthma off your back. Hemophilus influenzae vanquished. How high we have soared on the scientific imagination! These faces, and the faces of thousands of children like them, are our victories, hard won through pediatric research and through the contributions of members of our Society. We celebrate our successes. But let us be sure to give all our children the gift of flight. Let us watch every one soar above the plane of poverty, ignorance, and disease into that brilliant blue expanse of possibility. And how do we do that? Take a lesson, once again, from yeast.

\section{COHESION}

These are single yeasts: isolated, insular (Fig. 10, left panel). I can kill them easily, just by changing the environment. A little amphotericin, a new imidazole, and
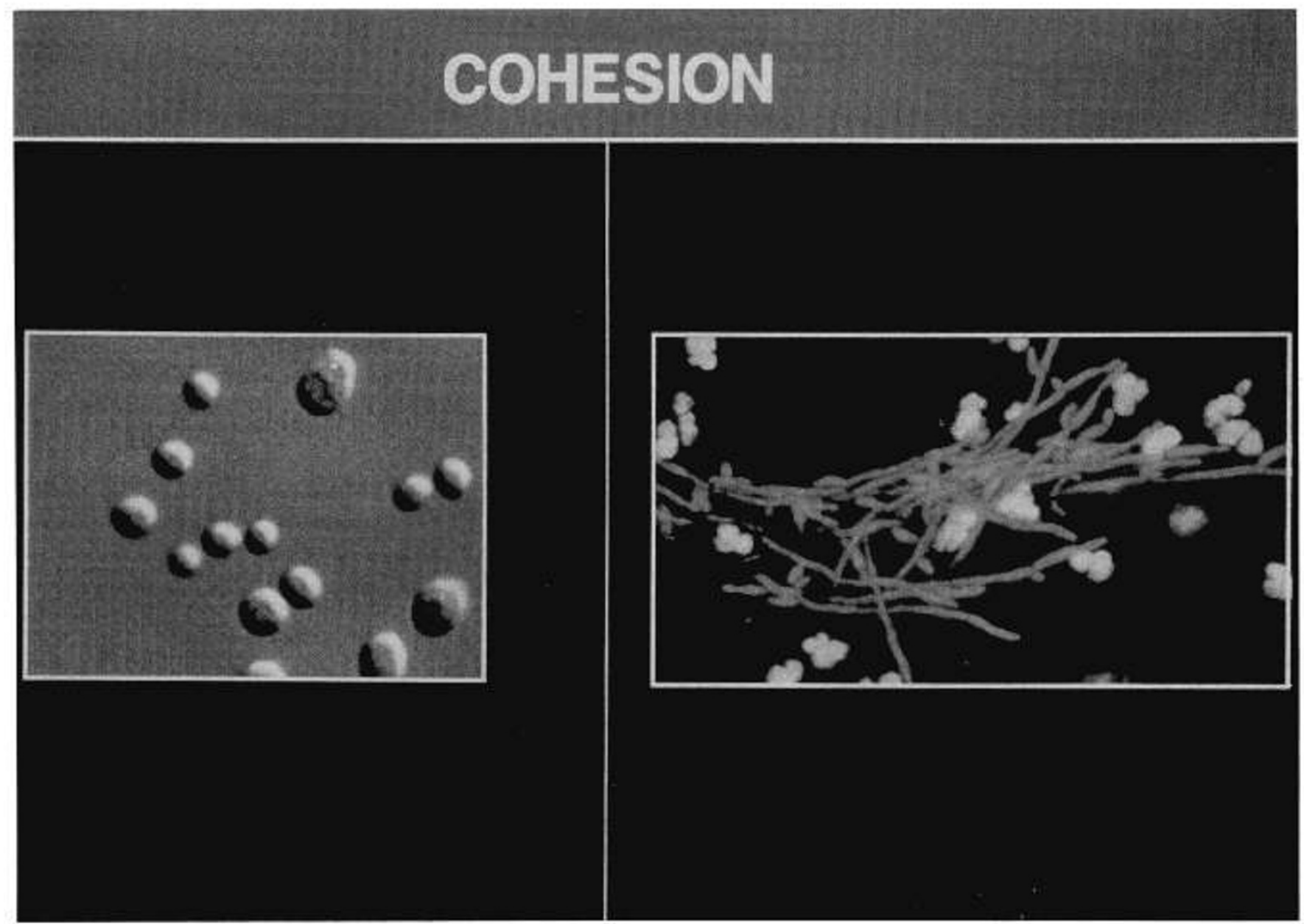

Figure 10. The left panel is reprinted from Kwon-Chung KJ, Bennett JE (eds) 1992 Medical Mycology. Lea and Febiger, Philadelphia, PA, plate 13.21, p 313; the right panel, from Beneke ES, Rippon JW, Rogers AL (eds) 1984 Human Mycoses. Upjohn Company, Kalamazoo, MI, plate 130, p 61, with permission of the respective publishers. 


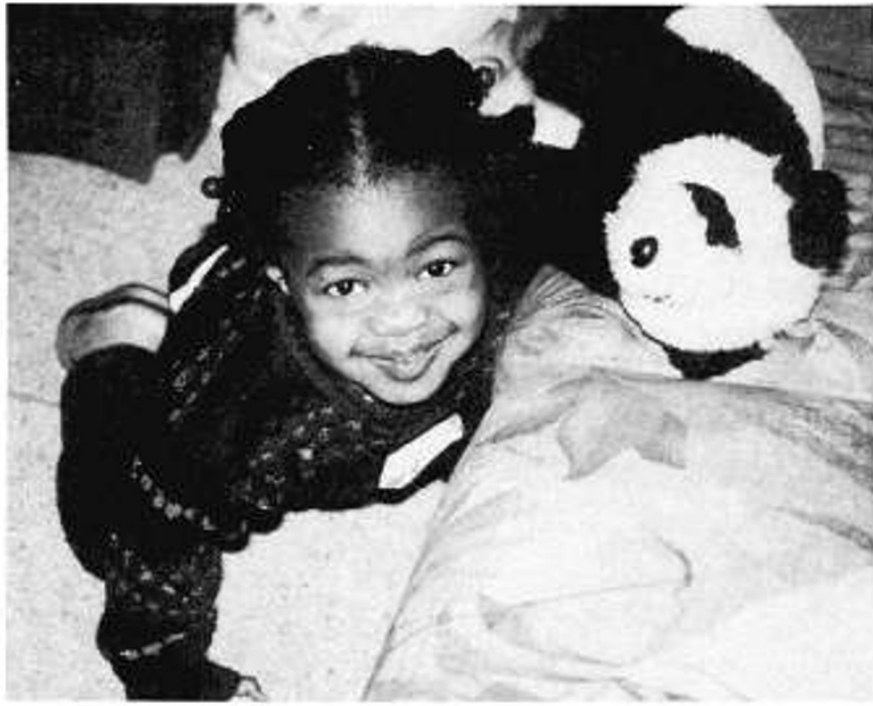

cellular synthesis breaks down completely. But this is yeast cohesion (Fig. 10, right panel), and this skein, this uncompromising network, is much more difficult to disrupt. So it must be with pediatrics. It cannot be my HMO against your hospital, your department against mine, private against academic. Given the upheaval and conflict in the medical profession, there will be many opportunities for divisiveness, anger, and confusion. But we must look beyond the immediate arena to the larger vista, and our loyalties must not deviate. The overarching vision is not power, prestige, or position. The vision is children. Your children, my children, the children we teach and the children we treat: sons and daughters all. We are a colony, a community of pediatricians with a common goal: that science must bring hope to children, and that we, as their champions, must speak with one voice for those without.

The words are those of Perri Klass (11), from her book, Other Women's Children, but the march and the battle and the victory must be ours:

"Imagine them all getting better. All through the hospital, the children get better. Their breathing gets easier, they poke their heads out of the oxygen tents and take deep breaths of room air. They pull the i.v.s out of their hands, their feet, their chests, their heads. No one needs antibiotics; the evil bacteria are dead. No one needs intravenous nutrition; they are all hungry for milk, baby food, hamburgers. Imagine them strong enough to jump from their beds and swarm through the corridors.... Imagine the corridors full of children, the big ones running, the toddlers toddling, the little ones crawling. No more fevers, no more wheezing, above all; no more pain ... And in every room, on every ward. Imagine them pouring out the front doors, the big ones now carrying the babies, reaching down to hold the hands of the toddlers, the whole pack disappearing down the street, leaving the hospital, with its humming lights and beeping monitors; leaving it behind."

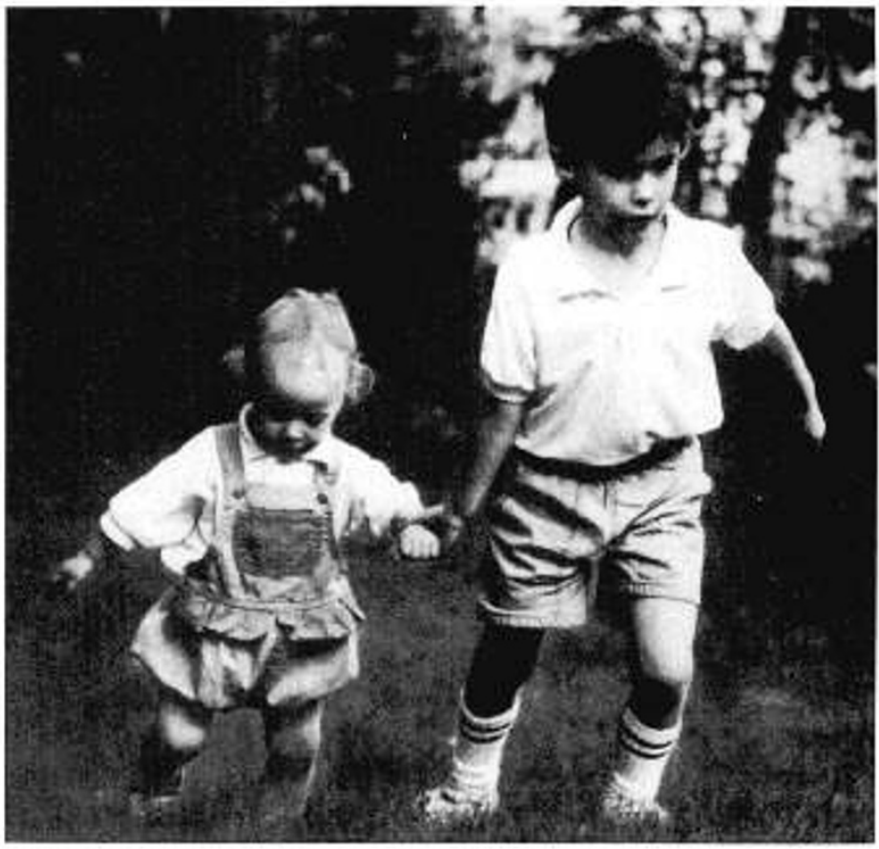

Resilience. Transformation. Cohesion. That message leaps across one billion years of evolution. That is the beauty of biology, the power of science, and the glory of pediatrics. Children first. And we must see it done.

Acknowledgments. I am grateful to Drs. Barbara Daniels and David Laxon and Drs. Edward Greene and Lonnie Neal for permission to use their children's pictures in this publication. Publication costs were supported by the American Legion and Women's Auxiliary Heart Research Foundation. Dr. Hostetter is the holder of the American Legion and Auxiliary Heart Research Chair in Pediatrics at the University of Minnesota, where she is Professor of Pediatrics and Microbiology and Director of the Division of Pediatric Infectious Diseases.

\section{REFERENCES}

1. Heidenreich F, Dierich MP 1985 Candida albicans and Candida stellatoidea, in contrast to other Candida species, bind $\mathrm{iC} 3 \mathrm{~b}$ and $\mathrm{C} 3 \mathrm{~d}$ but not C3b. Infect Immunol 50:598-600

2. Edwards JE Jr, Gaither TA, O'Shea JJ, Rotrosen D, Lawley TJ, Wright SA, Frank MM, Green I 1986 Expression of specific binding sites on Candida with functional and antigenic characteristics of human complement receptors. J Immunol 137:3577-3583

3. Hynes RO 1992 Integrins: versatility, modulation, and signaling in cell adhesion. Cell 69:11-25

4. Gilmore BJ, Retsinas EM, Lorenz JS, Hostetter MK 1988 An iC3b receptor on Candida albicans: structure, function, and correlates for pathogenicity. $\mathbf{J}$ Infect Dis 157:38-46

5. Hostetter MK, Lorenz JS, Preus L, Kendrick KE 1990 The iC3b receptor on Candida albicans: subcellular localization and modulation of receptor expression by sugars. J Infect Dis 161:761-768

6. Kiehn TE, Edwards FF, Armstrong D 1979 The prevalence of yeasts in clinical specimens from cancer patients. Am J Clin Pathol 73:518-521

7. Bendel CM, Hostetter MK 1993 Distinct mechanisms of epithelial adhesion for Candida albicans and Candida tropicalis. J Clin Invest 92:1840-1849

8. Bendel CM, Hostetter MK 1991 Correlation of adhesion and pathogenic potential in yeast. Pediatr Res 29:167A (abstr)

9. Hostetter MK, Bendel CM, McClellan M, Michael EJ 1992 Integrin analogs in Candida albicans, other Candida species, and Saccharomyces cerevisiae. J Cell Biochem 16F(suppl): 149

10. DeMuri G, Hostetter MK 1994 Evidence for a $\beta_{1}$ integrin in Candida tropicalis. Pediatr Res 35:178A (abstr)

11. Klass P 1990 Other Women's Children. Random House, New York, NY, p 283 